\title{
Comparison of cardiovascular protective effects of tropical seaweeds, Kappaphycus alvarezii, Caulerpa lentillifera, and Sargassum polycystum, on high- cholesterol/high-fat diet in rats
}

\begin{abstract}
This study was designed to investigate the comparative in vivo cardiovascular protective effects of red, green, and brown tropical seaweeds, namely, Kappaphycus alvarezii (or Eucheuma cottonii), Caulerpa lentillifera, and Sargassum polycystum, in rats fed on highcholesterol/high-fat (HCF) diets. Male Sprague-Dawley rats (weighing 260ї 300 迆) on the HCF diet had significantly increased body weight, plasma total cholesterol (TC), plasma lowdensity lipoprotein cholesterol (LDL-C), plasma triglycerides (TG), lipid peroxidation, and erythrocyte glutathione peroxidase (GSH-Px) and superoxide dismutase levels after 16 weeks. Supplementing 5\% seaweeds to HCF diet significantly reduced plasma TC (i 11.4\% to $\bar{\imath} 18.5 \%$ ), LDL-C (i $22 \%$ to $\bar{\imath} 49.3 \%$ ), and TG (i $33.7 \%$ to $\bar{\imath} 36.1 \%$ ) levels and significantly increased HDL-C levels (16.3ï 55\%). Among the seaweeds, S. polycystum showed the best anti-obesity and blood GSH-Px properties, K. alvarezii showed the best antihyperlipemic and in vivo antioxidation effects, and $\mathrm{C}$. lentillifera was most effective at reducing plasma TC. All seaweeds significantly reduced body weight gain, erythrocyte GSH-Px, and plasma lipid peroxidation of HCF diet rats towards the values of normal rats.
\end{abstract}

Keyword: Cardiovascular; Seaweeds; Rats; Hypercholesterol; Hyperlipidemia 